\title{
Simultaneous Detection of 2019 Novel Coronavirus and Influenza Virus by Double Fluorescent RT-PCR
}

\author{
Shasha Zhang, Xiaoli Sun, Wei Guo, Jianfeng Xu* \\ Panjin Centers for Disease Control/Panjin Center for Inspection and Testing, Panjin, China \\ Email address: \\ 250456075@qq.com (Shasha Zhang),2603867126@qq.com (Jianfeng Xu),912713958@qq.com (Xiaoli Sun), \\ $77847328 @$ qq.com (Wei Guo) \\ ${ }^{*}$ Corresponding author
}

\section{To cite this article:}

Shasha Zhang, Xiaoli Sun, Wei Guo, Jianfeng Xu. Simultaneous Detection of 2019 Novel Coronavirus and Influenza Virus by Double Fluorescent RT-PCR. American Journal of Laboratory Medicine. Vol. 5, No. 1, 2020, pp. 42-46. doi: 10.11648/j.ajlm.20200501.16

Received: March 6, 2020; Accepted: March 26, 2020; Published: April 13, 2020

\begin{abstract}
This paper introduces a method for simultaneous detection of 2019 novel coronavirus (2019-nCoV) and influenza virus A and influenza virus B (FluA/B) by dual fluorescent RT-PCR, providing some references for the current clinical first-line practice against the epidemic. More than 12000 samples of nasopharyngeal swabs, sputum and anal swabs were collected. All samples were inactivated at $60^{\circ} \mathrm{C}$ for $40 \mathrm{~min}$ before testing, so as to protect medical examine. Nucleic acid detection kits from two manufacturers of 2019-nCoV and FluA/B were selected for the detection. Carboxyfluorescein (FAM) and green fluorescent protein (VIC) labeled probes were used to achieve simultaneous detection of the four gene targets using a double fluorescent RT-PCR reaction system. According to the results of nucleic acid detection, there is no cross infection between 2019-nCoV and FluA/B. The CT value of novel coronavirus nucleic acid in anal swab greater than CT value of sputum greater than CT value of nasopharyngeal swab in the same patient. This paper introduces a method for rapid and simultaneous detection of 2019-nCoV and FluA/B by dual fluorescent RT-PCR. It was improved the detection efficiency and reduce the cost, which could be used for rapid and emergent detection of 2019-nCoV and FluA/B. Our experiment is fast and accurate, could make reference for nucleic acid detection medical diagnosis for clinical medical staff.
\end{abstract}

Keywords: 2019-nCoV, A/B Influenza Virus, Nucleic Acid Detection, Double Fluorescent RT-PCR

\section{Introduction}

"COVID-19", referred to as Corona Virus Disease 2019, is a pneumonia caused by infection of a novel coronavirus. [1-2]. Since December 2019, some hospitals in Wuhan, Hubei Province, have reported a number of pneumonia cases for unknown reasons due to exposure to the South China Seafood Market. So far, there have been more than 80,000 people infected by 2019 Novel Coronavirus in China, among whom more than 3,000 people died. Besides China, the epidemic situation in Italy, America, Spain, Germany, and Iran is worsening rapidly. The Director General of WHO said that the COVID-19 outbreak was evolving into a global pandemic [3-4]. Quick and accurate diagnosis on infection of the novel coronavirus is very important for assessment and control of COVID-19 situation in the world. This paper is mainly to introduce simultaneous detection of novel coronavirus and FluA/B by dual fluorescence RT-PCR method.

\section{Material and Methods}

\subsection{Material}

\subsubsection{Experiment Materials}

Samples: suspected clinical patients with fever from out-patient clinics of designated hospitals in this city, clinically diagnosed patients, close contacts, domestic and foreign people who returned to the city recently, and etc. Category of samples: nasopharyngeal swabs, sputum and anal swabs, total more than 12,000 samples.

\subsubsection{Main Reagent}

The 2019 novel coronavirus nucleic acid detection kit and the FluA / FluB nucleic acid detection kit were purchased from 
Shanghai BioGerm Medical Biotechnology Co. Ltd and Jiangsu Shuoshi Biotechnology Co., Ltd. The viral nucleic acid extraction kit was purchased from Xi'an Tianlong Science and Technology Ltd. and Jiangsu Shuoshi Biotechnology Co., Ltd. RNeasy RNA purification kit was from QIAGEN GmbH, Germany.

\subsubsection{Instrument}

ABI Q7 Real-time Fluorescence Quantitative PCR Instrument; ABI 7500 Real-time Fluorescence Quantitative PCR Instrument; Roche 480 Real-time Fluorescence Quantitative PCR Instrument; Lawson DHB-200 Armor Bead Bath; Xiamen Zhiwei GI 100DX Autoclave sterilizer; AC2-5S1 A2 Biosafety Cabinet of Esco Micro Pte Ltd., NP968 Nucleic Acid Extraction Instrument of Xi'an Tianlong Science and Technology Ltd.; SSNP-2000A Nucleic Acid Extraction Instrument of Jiangsu Shuoshi Biotechnology Co., Ltd.; Thermo ST16R High Speed Refrigerated Centrifuge, and etc.

\subsection{Method}

The experimental operations were conducted strictly in accordance with the "Technical Guidelines for Laboratory Detection of Novel Coronavirus Infected Pneumonia (Version 2), the "Notice of the General Office of National Health Commission on the Issuance of Biosafety Guidelines for Novel Coronavirus Laboratory (Version 2) and the "Diagnostic Criteria for Influenza WS285-2008. [5, 6, 7]

\subsubsection{Sample Pretreatment}

All test samples must be inactivated at $60^{\circ} \mathrm{C}$ for $40 \mathrm{~min}$.

\subsubsection{RNA extraction}

(1) manual extraction: RNeasy RNA purification kit was used according to the instructions for use.

(2) Automatic extraction: NP968 Nucleic Acid Extraction Instrument or SSNP-2000A Nucleic Acid Extraction Instrument, add $20 \mu \mathrm{L}$ of protease $\mathrm{K}$ and $150 \mu \mathrm{L}$ of the sample to be tested to the instrument.

\subsubsection{Detection of Viral Nucleic Acid}

ABIQ7, ABI7500 and Roche 480 Real-Time Fluorescence Quantitative PCR Instruments were used for nucleic acid amplification and detection. The reaction system of Shanghai BioGerm novel coronavirus and FluA/B virus detection kit: 12 $\mu \mathrm{L}$ of qRT-PCR reaction solution, $4 \mu \mathrm{L}$ of qRT-PCR enzyme mixture, $4 \mu \mathrm{L}$ of primer probe $2019-\mathrm{nCoV}$ or FluA/B, total 20 $\mu \mathrm{L}$. The reaction system of Shuoshi novel coronavirus and FluA/B virus kit: $7.5 \mu \mathrm{L}$ of RT-PCR reaction solution, $5 \mu \mathrm{L}$ of enzyme mixture, $4 \mu \mathrm{L}$ of novel coronavirus reaction solution or FluA/B reaction solution, $3.5 \mu \mathrm{L}$ of RNA enzyme water, total $20 \mu$.

\subsubsection{Quality Control}

Negative control and positive control were used for each test run, and different targets were adjusted for baseline threshold according to corresponding negative control. The $\mathrm{Ct}$ value of negative control was higher than the value in specified the specification or was not detected. For the positive control, the amplification curve was S-shaped, with $\mathrm{Ct}$ value lower than the specified value. For the same test, if all of above conditions were met, the test was valid; otherwise, the test was invalid.

\section{Result}

\subsection{General Information of the Four Kits}

All of the four kits for detection of novel coronavirus were of ORF and $\mathrm{N}$ genes, FAM channel was of ORF gene and VIC channel was of $\mathrm{N}$ gene. Flu A gene and Flu B gene were for detection of influenza A and influenza B. Flu A gene was detected through FAM channel, and Flu B gene was detected through VIC channel. A comparison of the four kits is shown in Table 1.

Table 1. Comparison of general information on the four kits.

\begin{tabular}{|c|c|c|}
\hline The reagent manufacturer & Bojie (Double Fluorescent RT-PCR) & Shuoshi (Double Fluorescent RT-PCR) \\
\hline Test items & 2019-nCoV & 2019-nCoV \\
\hline Target gene & Flu A, Flu B & Flu A, Flu B \\
\hline Nucleic acid extraction method & $\begin{array}{l}\text { Automatic extraction of magnetic beads; } \\
\text { Manual column extraction }\end{array}$ & $\begin{array}{l}\text { Automatic extraction of magnetic beads; } \\
\text { Manual column extraction }\end{array}$ \\
\hline $\begin{array}{l}\text { Fluorescence detection and } \\
\text { amplification cycle number }\end{array}$ & $55^{\circ} \mathrm{C}, 40$ cycles & $55^{\circ} \mathrm{C}, 45$ cycles \\
\hline+ & ORF1ab, $\mathrm{N}$ gene $\mathrm{C} \mathrm{t} \leq 35 \mathrm{~S}$ curve & $\begin{array}{l}\mathrm{Ct} \leq 35 \text { and } \mathrm{S} \text { curve growth, both of ORF1ab and } \mathrm{N} \text { meet the above } \\
\text { conditions }\end{array}$ \\
\hline Result & $\mathrm{Ct}>38$ or not detected & $\mathrm{Ct}>38$ or not detected \\
\hline determination & $\begin{array}{l}\text { S curve, and } 35<\mathrm{Ct} \leq 38 \text { Need to review; } \\
\text { If the review results are consistent, the } \\
\text { result is positive }\end{array}$ & $\begin{array}{l}\text { One of the channel } \mathrm{Ct} \leq 35 \text {, another channel is } 35<\mathrm{Ct} \leq 38 \text {, need to repeat } \\
\text { testing again, If the repeated testing show } \mathrm{Ct} \text { is still } 35-38 \text { and } \mathrm{S} \text { curve } \\
\text { growth, it is positive, otherwise it is negative. }\end{array}$ \\
\hline lowest detection Limit & $1 \times 10^{3}$ copies $/ \mathrm{mL}$ & $1 \times 10^{3}$ copies $/ \mathrm{mL}$ \\
\hline Linear detection range & $2 \times 10^{3}-1 \times 10^{8}$ copies $/ \mathrm{mL}$ & $2 \times 10^{3}-1 \times 10^{8}$ copies $/ \mathrm{mL}$ \\
\hline
\end{tabular}

\subsection{Analysis on the Test Results}

More than 12000 nasopharyngeal swabs, sputum and anal swabs were tested simultaneously for novel coronavirus and Flu A/B virus, and for the same sample, the two novel coronavirus detection kits gave the same results. Synchronous detection of Flu A/B infection with novel coronavirus showed that no Flu $\mathrm{A} / \mathrm{B}$ virus was detected in patients who were positive for the novel coronavirus, and no novel coronavirus 
was detected in patients who were positive for Flu A/B virus. Most of the submitted samples were negative for novel coronavirus and Flu A/B virus, as shown in Table 2 and Figure 1, and Figure 2. Nasopharyngeal swabs, sputum and anal swabs were collected at the same time for patients whose novel coronavirus was positive. Analysis of the test results revealed that for the same patient, the $\mathrm{Ct}$ value of amplification curve for anal swab $>\mathrm{Ct}$ value of the sputum $>$ $\mathrm{Ct}$ value (Figures 3 and 4)

Table 2. Test results of some samples.

\begin{tabular}{|c|c|c|c|c|}
\hline \multirow{2}{*}{ The reagent manufacturer } & \multicolumn{2}{|c|}{ Novel coronavirus detection kit } & \multicolumn{2}{|c|}{ FluA/B detection kit } \\
\hline & Bojie & Shuoshi & Bojie & Shuoshi \\
\hline CBYJG20200001 & - & - & - & - \\
\hline CBYJG20200002 & - & - & - & - \\
\hline CBYJG20200003 & - & - & - & - \\
\hline CBYJG20200004 & - & - & $+($ FluA $)$ & $+($ FluA $)$ \\
\hline CBYJG20200005 & - & - & - & - \\
\hline CBYJG20200006 & - & - & - & - \\
\hline CBYJG20200007 & - & - & - & - \\
\hline CBYJG20200008 & - & - & - & - \\
\hline CBYJG20200009 & - & - & - & - \\
\hline CBYJG202000010 & - & - & - & - \\
\hline CBYJG202000011 & - & - & - & - \\
\hline CBYJG202000012 & + & + & - & - \\
\hline CBYJG202000013 & - & - & - & - \\
\hline CBYJG202000014 & - & - & - & - \\
\hline CBYJG202000015 & - & - & - & - \\
\hline CBYJG202000016 & - & - & - & - \\
\hline CBYJG202000017 & - & - & - & - \\
\hline CBYJG202000018 & - & - & - & - \\
\hline CBYJG202000019 & + & + & - & - \\
\hline CBYJG202000020 & - & - & $+($ FluA $)$ & $+($ FluA $)$ \\
\hline
\end{tabular}

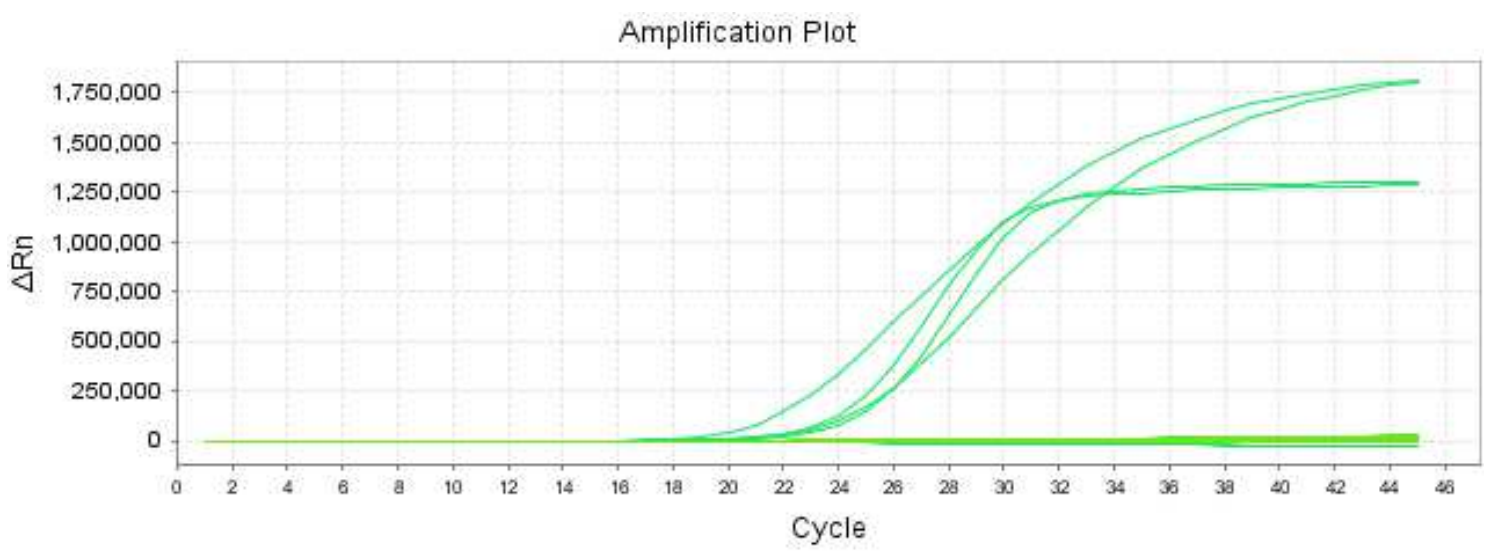

Figure 1. Curve for results from simultaneous detection of novel coronavirus and Flu A/B virus by BioGerm kit.

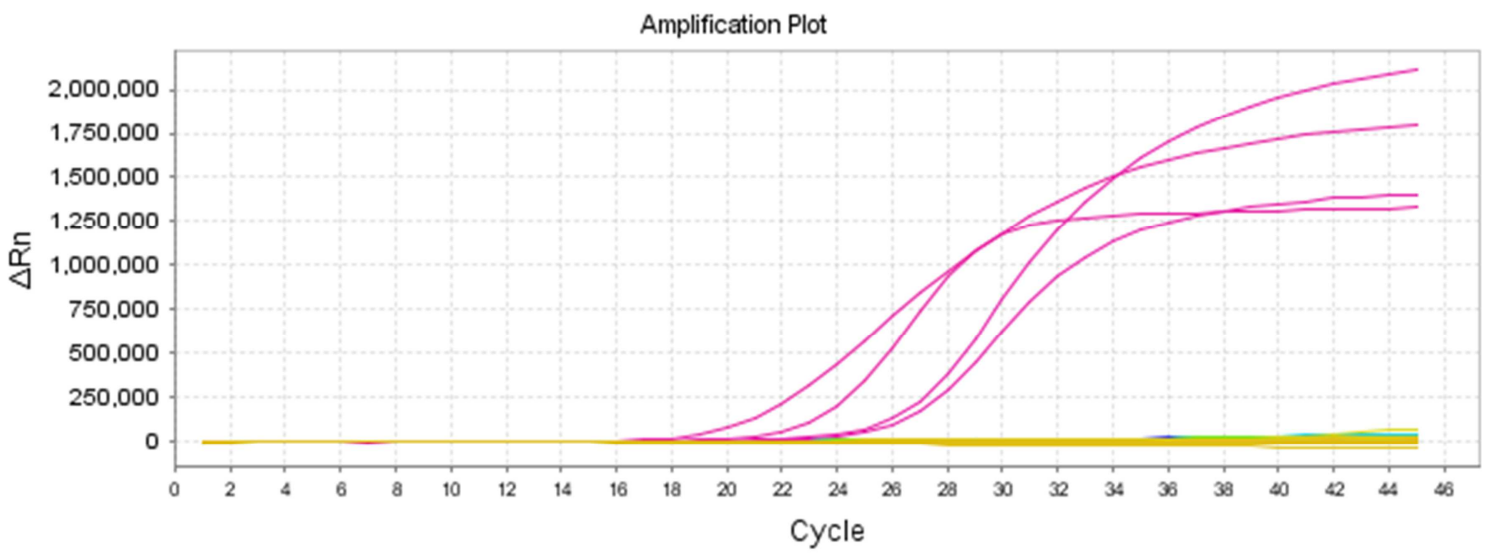

Figure 2. Curve for results from simultaneous detection of novel coronavirus and Flu A/B virus by Shuoshi kit. 


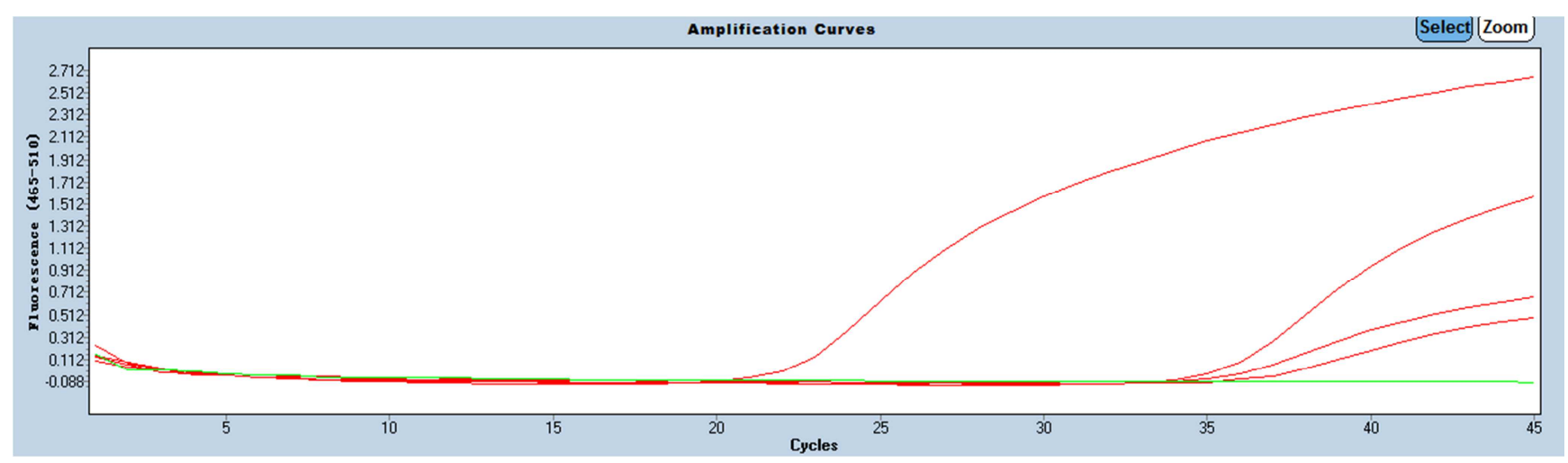

Figure 3. Curve for ORF1ab target gene results for a patient with positive results (positive control, anal swab, sputum, nasopharyngeal swab, negative control).

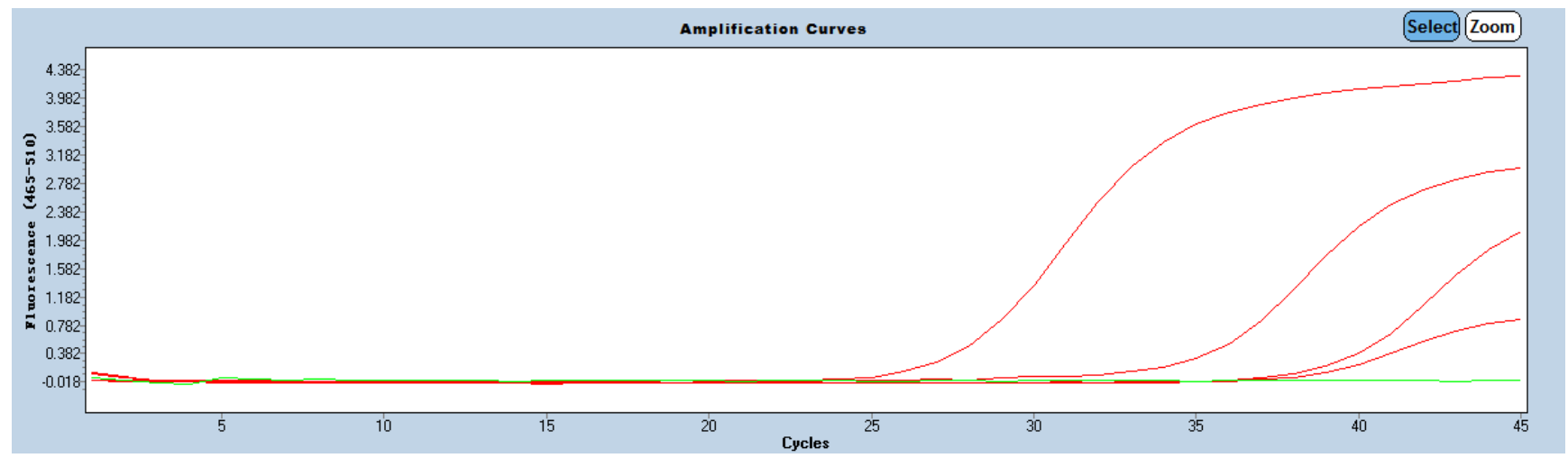

Figure 4. Curve for $N$ target gene results for a patient with positive results (positive control, anal swab, sputum, nasopharyngeal swab, negative control).

\section{Discussion}

The novel coronavirus continues to spread around the world, with confirmed cases on six continents except for Antarctica. According to the latest data released by WHO, new cases of COVID-19 have been reported in more than 200 countries and regions in the world, more than 100,000 people have been infected by novel coronavirus, and the number is still growing [8-9]. Due to the outbreak has developed rapidly, there should be a rapid and effective method for timely diagnosis among patients with different degrees of clinical symptoms and suspected patients. The novel coronavirus RNA detection can provide direct evidence for diagnosis. According to "Guidelines for Diagnosis and Treatment of COVID-19 (Version 7)" of the National Health Commission, suspected cases should be confirmed for either etiology or serology. 1 . Real-time fluorescent RT-PCR was used for cases with positive results of novel coronavirus nucleic acid detection. 2 . Virus gene sequencing is highly homologous with known novel coronavirus. 3. If the serum novel coronavirus-specific IgM antibody and IgG antibody were positive, the serum novel coronavirus-specific IgG antibody was 4 times or more higher in the recovery period than in the acute phase. [10] Serological test was added to the new version of guidelines for diagnosis and treatment. IgM antibodies produced by the infected people were mostly positive in 3-5 days after the infection, and $\mathrm{IgG}$ antibodies were generally acquired by the body immunity after recovery. In the laboratory, IgM and IgG antibody colloidal gold strip was used to detect the serum of a positive patient after recovery and discharge from the hospital. IgM and IgG antibody were still detected after the serum sample was diluted by 16 times, indicating that the patient was likely to infect others and still need to be isolated and observed for 14 days without interruption of detection. Real-time quantitative PCR is the best choice for detecting viral nucleic acid in the early stage of novel coronavirus infection (asymptomatic stage). Real-time fluorescent RT-PCR is for synchronous detection of novel coronavirus and influenza virus. The detection method has high sensitivity and specificity [11-12], and it can detect the same sample quickly and accurately at the same time, which may provide an important support for early clinical differentiation, early diagnosis and early treatment.

The laboratory tested more than 12000 samples for both novel coronavirus and Flu $\mathrm{A} / \mathrm{B}$ virus, and it was found that no Flu $\mathrm{A} / \mathrm{B}$ virus was detected in patients who were positive for the novel coronavirus, and no novel coronavirus was detected in patients who were positive for Flu A/B virus. This is just a reflection of clinical data. Based on current clinical data, there is no cross-infection between the novel coronavirus and Flue A/B. It has been verified in the laboratory that the novel coronavirus can be inactivated at $56^{\circ} \mathrm{C}$ for $30 \mathrm{~min}$. In this laboratory, all samples to be tested were inactivated at $60^{\circ} \mathrm{C}$ for $40 \mathrm{~min}$, so as to further protect the personnel for detection and avoid destructive effect on nucleic acid virus RNA. After the comparison on test results of nasopharyngeal swabs, sputum and anal swabs of positive patients, it was found that, for the same patient, the $\mathrm{Ct}$ value 
of the nucleic acid amplification curve of the anal swab was greater than the $\mathrm{Ct}$ value of the sputum, and the $\mathrm{Ct}$ value of the sputum was greater than the $\mathrm{Ct}$ value of the nasopharyngeal swab. It can be inferred that for an individual with samples of nasopharyngeal swab, sputum, and anal swab collected at the same time, the detection effect of anal swab was the best, followed by sputum, and then nasal and pharyngeal swab. However, clinically, the collection of anal swab is mostly limited by place. Although sputum samples are collected conveniently, many patients and the close contacts do not have sputum when they need to be collected, and they are often replaced by saliva, which affects the detection effect. The nose and pharynx samples were collected at the same time. Although the sampling was convenient, the virus bearing capacity of the nasopharynx was limited, the $\mathrm{Ct}$ value of the amplification curve was low, and omission was easy to occur. Therefore, it was necessary to adopt the plan of sampling and repeated detection on alternate days for suspected patients. At the same time, in the case of "negative converted to positive" after the patient was cured and discharged from the hospital, sampling and re-examination should be carried out evert two days until the nasopharyngeal swab, sputum and anal swab were completely negative for nucleic acid detection, and then regular monitoring should be conducted for a period of time.

\section{Author Contributions}

The submission has been received explicitly from all co-authors. And authors whose names appear on the submission have contributed sufficiently to the scientific work and therefore share collective responsibility and accountability for the results.

\section{Conflict of Interest}

The authors declare that they have no conflict of interest.

\section{Informed Consent}

The manuscript does not contain experiments using animals and human performed by any of the authors. Informed consent was obtained from all individual participants included in the study.

\section{Acknowledgements}

Shasha Zhang and co-authors thanks to Panjin CDC. And every medical profession in the prevention and control of COVID-19 epidemic in the whole world.

\section{References}

[1] Zhu N, Zhang D, Wang W, Li X, et al. A Novel Coronavirus from Patients with Pneumonia in China, 2019 N Engl J Med. 2020 pp. 727-733.

[2] Huang C, Wang Y, Li X, et al. Clinical features of patients infected with 2019 novel coronavirus in Wuhan, China. Lancet. 2020 pp. 497-506.

[3] Dayoo Ocean network https://baijiahao.baidu.com/s?id=1659869159132622751\&wfr $=$ spider $\&$ for $=\mathrm{pc}$

[4] Zhang N, Wang L, Deng X, et al. Recent advances in the detection of respiratory virus infection in humans. J Med Virol. 2020; 92 pp. 408-417.

[5] General Office of China Health and Health Commission, State Administration of Traditional Chinese Medicine. Technical guidelines for laboratory testing of COVID-19 (second edition) (2020-01-22)

http://www.nhc.gov.cn/xcs/zhengcwj/202001/c67cfe29ecf147 $0 \mathrm{e} 8 \mathrm{c} 7 \mathrm{fc} 47 \mathrm{~d} 3 \mathrm{~b} 751 \mathrm{e} 88 . \mathrm{shtml}$

[6] General Office of China Health and Health Commission, State Administration of Traditional Chinese Medicine. Laboratory biosafety guidelines of 2019-nCoV (second edition) (2020-01-23)

http://www.nhc.gov.cn/qjjys/s7948/202001/0909555408d842a 58828611dde2e6a26.shtml

[7] Ministry of Health of the PRC Diagnostic criteria for influenza WS285-2008.

[8] phoenix http://feng.ifeng.com/c/7uPEzrxc9Bi

[9] Beijing daily client http://mbd.baidu.com/newspage/data/landingsuper?context $=\%$ 7B\%22nid\%22\%3A\%22news_8695525602424460969\%22\% 7D\&n_type $=0 \& p \_$from $=1$

[10] General Office of China Health and Health Commission, State Administration of Traditional Chinese Medicine. Diagnosis and treatment plan of COVID-19 (Trial version 7) (2020-03-04) http://www.nhc.gov.cn/yzygj/s7653p/202003/46c9294a7dfe4c ef80dc7f5912eb1989.shtml

[11] Corman VM, Landt O, Kaiser M, Molenkamp R, et al. Detection of 2019 novel coronavirus $(2019-\mathrm{nCoV})$ by real-time RT-PCR. Euro Surveill. 2020 pp. 1560-7917.

[12] LI Jin Ming. Real time Quantitative PCR Beijing Science Press, 2016. 